\title{
Mental images can be ambiguous: Reconstruals and reference-frame reversals
}

\author{
MARY A. PETERSON, JOHN F. KIHLSTROM, PATRICIA M. ROSE, and MARTHA L. GLISKY \\ University of Arizona, Tucson, Arizona
}

\begin{abstract}
Philosophers and psychologists have debated whether or not mental images of ambiguous figures are reversible as pictures of such figures are. Previously, empirical evidence both pro (Finke, Pinker, \& Farah, 1989) and con (Chambers \& Reisberg, 1985) has been obtained. In a series of four experiments, we identify the conditions under which images of classic ambiguous figures like the duck/rabbit and the snail/elephant are reversible. We distinguish between two types of reversal: those that entail a change in reference-frame specification as well as a reconstrual of image components (reference-frame realignments) and those that entail reconstruals only (reconstruals). We show that reference-frame realignments can occur in imagery, particularly if observers are given an explicit or an implicit suggestion; and that reconstruals of images occur commonly, regardless of experimental conditions. In addition, we show that images constructed from good parts are more likely to reverse than images constructed from poor parts. On the basis of these results, we propose a functional organization of shape memory that is consistent with shape recognition findings as well as with our reversal findings.
\end{abstract}

Given that imagery theories address questions regarding the nature of the imagined representation, theories of shape recognition are implicit in theories of imagery (see Kosslyn, Pinker, Smith, \& Shwartz, 1979). Indeed, because imagined shapes must be generated by memory structures, studies of the attributes of mental images (henceforth also just "images") may yield information about the characteristics of memory representations of shape. This issue underlies the current debate about whether mental images can be ambiguous-that is, whether such images can be reversed, reconstrued, or reinterpreted, just as pictures can be.

Some philosophers (e.g., Casey, 1976; Fodor, 1981) and psychologists (e.g., Kolers, 1983) have argued that mental images cannot be ambiguous, but empirical data have been lacking until recently. Chambers and Reisberg (1985) found that not 1 of 35 observers who originally saw only one of the two potential interpretations of the duck/rabbit ambiguous figure (Jastrow, 1900) could find the alternative interpretation in their memory image of the figure. Hence, they concluded that mental images of ambiguous pictures refer unambiguously to only one potential interpretation of the picture. Further, they argued that in the process of creating images, observers access shape representations by means of semantic representations, and that the two cannot be decoupled: Having seen a rabbit in a picture, one subsequently accesses a mental image

\footnotetext{
This research was supported in part by Grant BNS-8810997 to M. A. Peterson from the National Science Foundation and the Air Force Office of Scientific Research, and in part by Grant MH-35856 to J. F. Kihlstrom from the National Institutes of Mental Health. We thank Julian Hochberg for encouraging the undertaking of these experiments and Erin Harvey for helping test the subjects in Experiment 1. Correspondence should be addressed to Mary A. Peterson, Department of Psychology, University of Arizona, Tucson, AZ 85721 (e-mail: mapeters@arizrvax.bitnet).
}

of a rabbit that cannot be transformed into an image of a duck. According to this view, those of us who are familiar with the duck/rabbit figure, and might suppose that we are able to imagine a reversal, are simply replacing one image with another, rather than discovering an alternative interpretation of a single mental image.

Although Chambers and Reisberg's (1985) findings were quite striking, Finke, Pinker, and Farah (1989) demonstrated that semantic and structural representations of objects can be separated. When asked to manipulate and combine alphanumeric characters or simple geometric shapes in imagery, their observers discovered a number of new shapes in the resultant configurations: for example, a particular arrangement of the letters $J$ and $D$ was interpreted as an umbrella. In reconciling their findings with those of Chambers and Reisberg (1985), Finke et al. (1989) suggested that reversals of the duck/rabbit figure might require low-level global perceptual processes that are inaccessible to imagery processes, which may interact with high-level visual processes only. However, Finke et al. offered no evidence in support of this conjecture, nor did they examine the reversibility of mental images of classical reversible figures in any of their experiments.

Understanding the relationship between the structural and denotative aspects of images should improve our understanding both of the structure of shape representations and of the processes of shape recognition. Accordingly, in this article we report a series of experiments in which we attempted to identify the processes that might lead to such discrepant results as those obtained by Chambers and Reisberg (1985) and Finke et al. (1989). Our analysis focuses on three factors: (1) the type of reversal demanded by the stimulus; (2) the strategies deployed by subjects during the imagery task; and (3) the quality of the image components. 


\section{Types of Reversal}

In analyzing ambiguous figures, it is important to make a distinction between different types of reversal (see, e.g., Price, 1969). For the purposes of this paper, we concentrate on the distinction between reversals that entail assigning a new interpretation to the image components only, and reversals that entail a change in object-centered directions, such as the top/bottom or front/back of the image. Henceforth, we will refer to the former as reconstruals and the latter as reference-frame realignments. Both reconstruals and reference-frame realignments will be considered subsets of the general term reversal. Note that the term reference frame is being used in a restricted sense here, to refer to the specifications of the top and bottom and the front and back of a shape. We do not use it more generally to refer to axes of elongation or symmetry that might be fit to a shape, as others have done (cf. Marr, 1982).

Reversals of the duck/rabbit figure used by Chambers and Reisberg (1985), shown in Figure 1A, entail both component reconstrual and a change in reference-frame specifications, because the front of the duck's head becomes the back of the rabbit's head (or vice versa). We regard the reversals of the figures used by Finke et al. (1989) as predominantly reconstruals, for two reasons. First, although the reference frames of some of the components were changed in the constructed figure, the instructions made clear which reference frame to employ for the constructed figure (e.g., subjects were instructed to put the rotated $D$ "on top of " the $V$ ); hence, reversals of the constructed shape's reference frame were not required. Second, to the extent that the alphanumeric characters were treated as components of emergent shapes, they may have themselves been reference-frame free. (Cf. Biederman's, 1987, theory of shape recognition for the claim that reference frames are not specified for individual components of shapes, but only for the shape as a whole.) It may be that reconstruals occur more readily in imagery than reversals entailing reference-frame realignments, but the reasons for this may have nothing to do with the putative differences between high- and lowlevel vision, proposed by Finke et al. (1989).

\section{Cognitive Strategies}

A related issue is the question of the type of strategies employed by observers during the imagery task. Both Chambers and Reisberg (1985) and Finke et al. (1989) familiarized their observers with the phenomenon of ambiguity by showing them the Necker cube, the Mach book, and the Rubin vase/faces stimuli, shown in Figure 2. However, while these figures are all ambiguous, they are not all ambiguous in the same way, or in the same way as the duck/rabbit stimulus. For example, reversals of both the Necker cube and the Mach book entail reference-frame realignment, but they require no reconstrual of the meaning of individual components. (Indeed, these figures might be single-component forms, as Peterson and Gibson, 1991, point out.) Reversals of figure/ground in the Rubin figure entail a change in the identity of the components as the outside of the previously defined shape becomes the inside of the new shape (Hoffman \& Richards, 1985). Hence, any strategies implicitly suggested to subjects by these familiarization figures might be expected to be ineffective with the duck/rabbit figure, which requires both realignment of the reference frame and reconstrual of what is denoted by fixed components.

Chambers and Reisberg (1985) did show the chef/dog figure to their subjects after they had already formed their mental images of the duck/rabbit. Reversal of the chef/dog figure entails a reference-frame realignment as well as a part reconstrual, in that the top of the chef's hat becomes the back of the dog, as is shown in Figure 1B. But notice that the object-centered top is not the same as the viewerand environmentally centered top for either the chef or the dog, whereas the object-centered top of the duck/rabbit figure corresponds to the viewer- and environmentally centered top. Notice also that reversal from the chef into the dog requires a $90^{\circ}$ respecification of the objectcentered top, whereas reversal of the duck/rabbit figure requires a $180^{\circ}$ front-to-back reversal, so the chef/dog figure might in fact suggest some misleading reversal strategies. Thus, it is possible that certain aspects of Chambers and Reisberg's experiments operated to make reference-frame reversals less likely than would have been the case had a more appropriate strategy been suggested.

In fact, the importance of strategies is strongly suggested by experiments conducted by Hyman and Neisser (1991) and Reisberg and Chambers (1991). Hyman and Neisser (1991) asked their subjects to imagine the duck/ rabbit figure, and then to consider the front of the animal they were viewing to be the back of another animal. Under these circumstances, over half of their observers reversed the image. Similar findings were obtained by Reisberg and Chambers (1991), using different figures. For example, Reisberg and Chambers showed observers a familiar shape (e.g., a map of the state of Texas) that was rotated from its canonical orientation so that the object-centered and viewer-centered top did not coincide. This rotated familiar shape was presented among a series of "setting" figures that led observers to see it as a meaningless figure. Subjects who were asked to rotate the image so that the object-centered top of the Texas shape was uppermost in the image were unable to recognize the image as depicting the state of Texas. However, some proportion of subjects who were asked to consider the top of the rotated image as the top of the shape were able to recognize that the image depicted the state of Texas.

Thus, the interpretation assigned to an image can be changed when the appropriate strategy is suggested explicitly. Reisberg and Chambers (1991) argue that, in response to these instructions, subjects substitute one image for another, rather than reverse the original image. They argue further that this reversal process differs from the reversal processes operating in perception, where reversals occur spontaneously (although research by Rock and his colleagues [Girgus, Rock, \& Egatz, 1977; Rock \& 


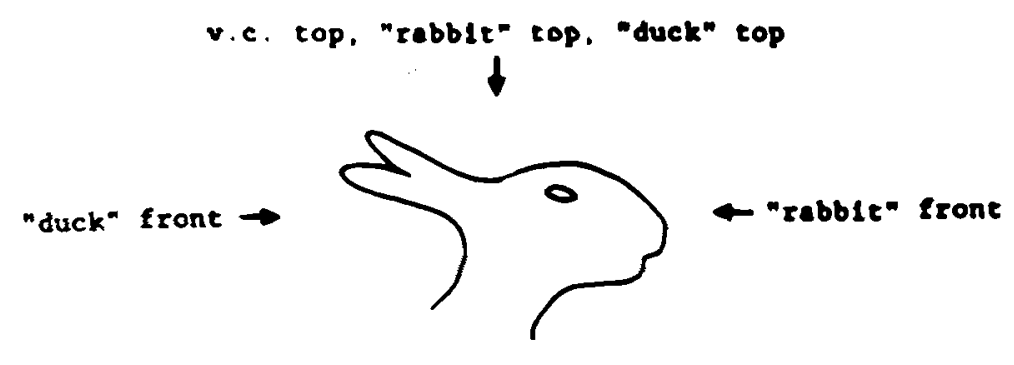

a.

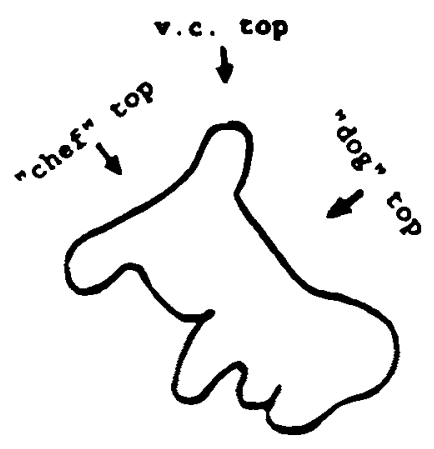

b.

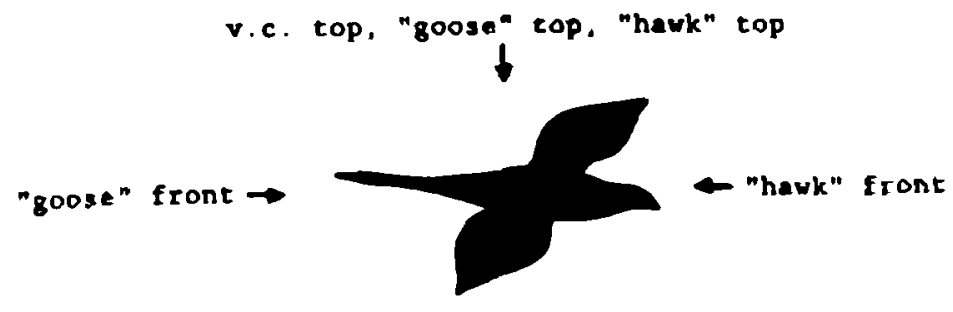

c.

Figure 1. (A) Jestrow duck/rabbit figure. (B) Chef/dog figure. (C) Goos/hawk figwe. The viewer-centered (V.c.) and object-centered reference trumes for each of these two diternotive interpretations are indicated. Environmental reference frames were the same as the viewer-centered refereoce frames.

Mitchner, in press] demonstrates that the reversals of many figures may not be perceived spontaneously).

Unfortunately, neither Reisberg and Chambers (1991) nor Hyman and Neisser (1991) attempted to determine whether both reconstruals and reference-frame realignments were equally affected by the hints subjects were given. A comparison of reconstrials and reversals of classical reversible figures might clarify the differences between Reisberg and Chambers's (1991) failure to find reversals in imagery and Finke et al.'s (1989) success. It is possible that reconstruals, such as those examined by Finke et al., may be less open to influence by the demonstration figures used or by the hints given in the course of the experiment. Accordingly, in the following experi- ments, we examined whether or not reference-frame realignments and/or reconstruals of an image are influenced by the type of demonstration figures and hints used.

\section{Quality of Image Components}

A final difference between the experiments of Chambers and Reisberg (1985) and Finke et al. (1989) has to do with the quality of the pictorial components manipulated in imagery. The subjects in the Finke et al. study viewed alphanumeric characters and other familiar objects, whereas those in the Chambers and Reisberg (1985) study viewed an unfamiliar, and rather idiosyncratic, duck (or rabbit). Moreover, Chambers and Reisberg cautioned their subjects to remember the picture exactly as it was presented, 


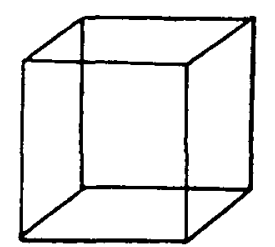

a.

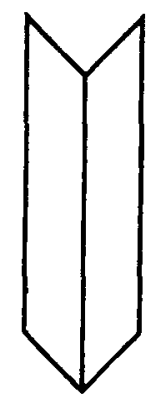

c.

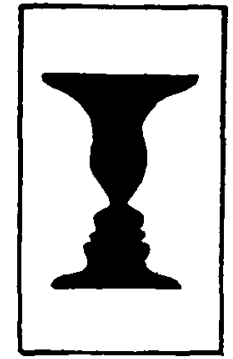

b.

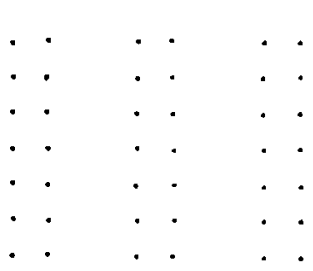

d.

Figure 2. (A) Necker cube. (B) Rubin vase/faces figure/ground stimulus. (C) Mach book. (D) Grid used in the parts conditions of Experiment 2.

so that they might be able to draw it later; Finke et al. (1989) gave their subjects no such instruction. These differences may well be critical. For example, both the familiarity of the image and the fidelity demanded in retention instructions affect performance on imagery tasks (see, e.g., Folk \& Luce, 1987; Peterson \& Weidenbacher, 1987; Shepard \& Cooper, 1982; Shepard \& Metzler, 1988).

Perception theorists generally agree that reinterpretations of entire shapes can be precipitated by reinterpretations of their individual components (e.g., Feldman \& Ballard, 1982; Hochberg, 1968; Simon, 1967). Accordingly, individual components may be more likely to be reinterpreted if attention can be focused on one component in isolation from the others. Imagery may be capable of providing such a condition. Research by Kosslyn (1980; Kosslyn, Reiser, Farah, \& Fliegel, 1983) has shown that images fade with time and must be regenerated if they are to be maintained. If the components of an image are familiar, as they were in the Finke et al. (1989) studies, observers may have been able to focus their attention on individual components, thereby allowing the other components to fade, because they knew they could easily regenerate those familiar components when necessary. In agreement with this explanation, Peterson and Weidenbacher (1987) have demonstrated that images of familiar shapes may be generated faster than images of unfamiliar shapes. On the other hand, Chambers and Reisberg (1985) imposed rigorous memory demands on their observers by warning them not to distort their images in accord with their interpretation of them, and by telling them that they would later be required to draw the original shapes from memory. These

strict fidelity instructions may have curbed any tendency to focus attention on individual parts of the image.

Of course, the familiarity of the components of stimuli such as the duck/rabbit can never be equated to that of the alphanumeric characters used by Finke et al. (1989). However, the effects of familiarity may be mimicked by manipulating the quality, or goodness, of the component parts of a figure. It is generally agreed that the minima of curvature delimit the perceptually relevant parts of a contour (Biederman, 1987; Hoffman \& Richards, 1985; Marr, 1977). Accordingly, we varied the quality of the components of our stimulus figures by partitioning them into three parts at the minima of curvature along the contour, hoping that the parts so identified would be viewed as good, if not exactly familiar. As a comparison, we also partitioned our figures into poor parts, at locations other than the minima of curvature. (See Figure 3.)

\section{Overview}

The experiments reported below all address the question of whether or not images can be reversed, and under what conditions. In order to avoid introducing new stimulus figures into the debate, we focused three of our experiments on the Jastrow (1900) duck/rabbit figure employed by Chambers and Reisberg (1985), which requires both component reconstrual and reference-frame realignment. In Experiments 1-3, we examined reversals of the duck/ rabbit image by observers presented with a full version of the stimulus. In Experiments 1 and 2, we also examined reversals by subjects who constructed their images from successively presented good or poor parts. In Experiment 4, we employed Fisher's (1976) snail/elephant figure, whose reversal requires component reconstrual only, without reference-frame realignment, to examine the generalizability of the results obtained in Experiments 1-3.
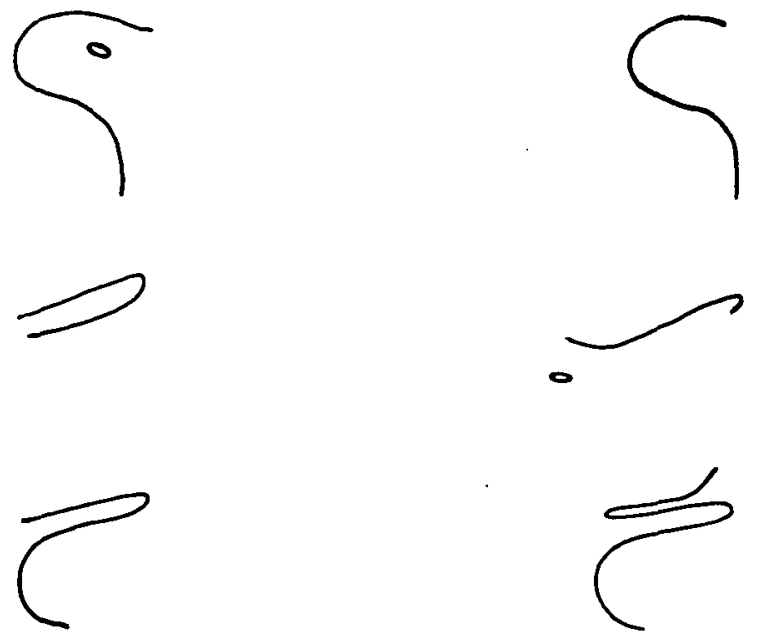

a.

b.

Figure 3. Parts shown to subjects in (A) good parts and (B) poor parts conditions. Connection markers are not shown. 


\section{EXPERIMENT 1}

The purpose of Experiment 1 was to replicate and extend the study of Chambers and Reisberg (1985), examining reversals in imagery for subjects who viewed a full version of the duck/rabbit stimulus figure. This full-version condition replicated the procedures of Chambers and Reisberg, with one exception. Among the demonstration figures, we replaced the Mach book with the goose/hawk figure, adapted from Tinbergen (1948), shown in Figure 1C. Reversal of the goose/hawk figure entails reversing the front/ back relations in the reference frame, as well as reconstruing certain components-exactly the strategy required for reversing the duck/rabbit figure. Accordingly, we predicted that presentation of the goose/hawk figure would increase the likelihood of reversing the duck/rabbit image. A second purpose of Experiment 1 was to compare reversals in imagery for subjects who viewed the figure broken into good versus poor parts along the contour. Third, following the procedures employed by Chambers and Reisberg (1985), this experiment also classified subjects according to mental imagery ability. However, whereas Chambers and Reisberg assessed only the vividness of mental imagery, we added an assessment of imagery control (Kihlstrom, Glisky, Peterson, Harvey, \& Rose, 1991).

\section{Method}

Subjects. The subjects for this experiment were 60 undergraduate students at the University of Arizona, who volunteered in partial fulfillment of the research requirement of their introductory psychology course. These subjects were selected from among 730 students who had completed two imagery questionnaires, Marks's Vividness of Visual Imagery Questionnaire (VVIQ; Marks, 1973) and Gordon's Test of Visual Imagery Control (TVIC; Gordon, 1949) during introductory class survey sessions earlier in the semester. Subjects were classified as high visualizers if they scored in the first quartile of both the VVIQ (24 or below) and the TVIC (16 or below); they were classified as low visualizers if they scored in the fourth quartile of both scales (VVIQ, 39 or above; TVIC, 28 or above). The subjects were tested in the imagery experiment individually.

Stimuli. Our stimuli were the three versions of the duck/rabbit figure shown in Figures 1A and 3. The good parts version, shown in Figure 3A, was created by partitioning the contour at a subset of the minima of curvature. The poor parts version, shown in Figure 3B, was created by partitioning the contour at regions that did not correspond to minima of curvature.

Our intuitions that these were good and poor parts were corroborated by a pilot study in which we showed 26 observers the full version of the duck/rabbit figure along with both sets of parts. These observers were asked to decide which set of parts was most natural, and to rate the naturalness of the parts in both sets on a 1-7 scale, with 1 indicating very natural, and 7 indicating very unnatural. We found that all but 1 of the observers chose the good parts as being the most natural part set. In addition, observers rated the good parts as more natural than the poor parts $[2.53$ vs. $5.77 ; t(25)=9.86$, $p<.001]^{1}$

Procedure. At the beginning of the experimental session, the subjects were first shown black-and-white line drawings of the Necker cube, the Rubin figure/ground stimulus, and the goose/hawk figure (Figures $2 \mathrm{~A}, 2 \mathrm{~B}$, and $1 \mathrm{C}$ ) in order to acquaint them with ambiguous and reversible figures. The order of presentation of these examples was counterbalanced. All subjects were required to see both interpretations of the demonstration figures, and to point out their features to the experimenter. If subjects failed to report both interpretations, the experimenter pointed out the parts of each. The subjects were assigned to one of three treatment groups, with 10 high and 10 low visualizers in each group.

Full-version condition. One group of subjects viewed the full version of the duck/rabbit figure (Figure IA) for $5 \mathrm{sec}$. They were instructed to form an accurate mental picture of the figure and were informed that they would be asked to draw it later. The subjects were permitted to take as long as was necessary to consolidate their mental images. After the subjects indicated that they were ready to go on, we asked them whether their images resembled anything familiar. Those who reported both duck and rabbit interpretations were eliminated because of the possibility that they had seen both interpretations while looking at the picture. ${ }^{2}$ Next, the subjects were shown the chef/dog figure (Figure IB) used by Chambers and Reisberg (1985), and they were required to see both interpretations as before. Following this demonstration, the subjects verified that their images were still clear (all reported affirmatively) and then responded to a series of questions.

1. A postdemonstration question: The subjects were first asked if they could find an alternative interpretation for the image, as they had for the chef/dog figure.

2. Subjects who were unable to report an alternative interpretation were then given a series of attention hints used by Chambers and Reisberg (1985). They were asked to direct their attention to the left and right sides of the image, and to report whether the image looked like anything different with attention directed toward those regions.

3. Subjects who were still unable to report an alternative interpretation were given the reference-frame hint used by Hyman and Neisser (1991). They were asked to consider the back of the head of the animal they had already seen as the front of the head of some other animal.

After these questions, all subjects were asked to draw the image. When they were finished, they were asked whether the drawing resembled anything else. At this point, the subjects were debriefed and dismissed.

Good and poor parts conditions. In these conditions, subjects saw successive presentations of either good parts (Figure 3A) or poor parts (Figure 3B) of the duck/rabbit figure, instead of the full version, and they were asked to form a single mental image from three parts shown separately. In order to reduce the demands for representational fidelity (so that the subjects might be more free to attend to individual parts in isolation), we did not tell the subjects in these conditions that they would be required to draw the entire image later.

The subjects viewed each of the three parts for $15 \mathrm{sec}$. Each part was marked at the ends that would be connected to another part; the marks were a "T," an "X," and a dot. The experimenter identified these connection markers while the subjects viewed the component and stressed that the markers only needed to be remembered until the next part was connected properly, at which point they could be deleted from the image. After the subjects indicated that they had consolidated the full image, the experimenter asked them to confirm that all the parts were visible (all did so). At this point, the subjects were asked a series of questions. (They, unlike subjects in the full-version condition, were not shown the chef/dog figure.)

1. Early questions: First, the subjects were asked whether their images resembled anything familiar. After they gave one interpretation of the image, they were informed that the image was ambiguous and were asked to identify any other objects that it resembled. These questions are modeled after the post-chef/dog questions used in the full-version condition.

2. Parts questions: Subjects who did not report a second interpretation during the early questions were given instructions directing them to pay attention to each of the three parts, individually or in pairs, to determine whether the figure as a whole could resem- 
ble anything else. These questions were not used in the study by Chambers and Reisberg (1985), nor were they given in the fullversion condition.

3. The parts questions were followed by attention and referenceframe hints, as in the full-version condition. Following the questions, the subjects drew the image, as subjects in the full-version condition had.

Data analysis. Our subjects offered many interpretations of their images other than, or in addition to, ducks and rabbits-for example, " "person with hair streaming behind," "deer," "dog," "animal with horns," and "fish." Of course, some interpretations were more valid than others. We considered an interpretation to be valid if it met a two-part criterion: the interpretation had to be an interpretation of the entire image, not just a single part; and the interpretation had to identify a particular shape depicted by the image, and not merely describe the image in general terms. Thus, the interpretations listed above were considered to be valid interpretations, but "nose," "fingers," "shape," and "line" were not. Two authors served as raters (M.L.G. and P.M.R.; interrater agreement $=.83$ ), with the first author resolving their disagreements according to a conservative criterion. Reversals between any two valid interpretations (including duck and rabbit interpretations) were scored as either referenceframe realignments or reconstruals, whichever was appropriate.

Since Chambers and Reisberg (1985) only analyzed duck/rabbit (reference-frame) reversals, we show duck/rabbit reversals separately in the top half of Table 1 . The values shown at the bottom of the table (for all reversals) include both reference-frame realignments and reconstruals. ${ }^{3}$ When subjects reported more than one valid reversal, the reversal entered at the bottom was the first alternation from one valid interpretation to another.

\section{Results and Discussion}

Duck/rabbit reversals. Table 1 (top half) shows the proportion of subjects reporting duck/rabbit reversals (e.g., reference-frame realignments). Because there were no effects of mental imagery ability, whether of vividness or

Table 1

Imagery Reversals Reported in Experiment 1

\begin{tabular}{cccc}
\hline & \multicolumn{3}{c}{ Condition } \\
\cline { 2 - 4 } & Full & Good & Poor \\
Questions & Version & Parts & Parts \\
\hline
\end{tabular}

Duck/Rabbit Reversals

(Reference-Frame Realignments)

Postdemonstration

.20

Early

Parts

Attention hints

Total before reference-frame hint

Reference-frame hint

Total in imagery

Drawing

\begin{tabular}{r}
.15 \\
\hline .35 \\
.05 \\
\hline .40 \\
.35
\end{tabular}

\begin{tabular}{r}
.15 \\
.05 \\
.00 \\
\hline .20 \\
.15 \\
\hline .35 \\
.15
\end{tabular}

.10

.00

.00

.10

.00

.10

All Reversals

Postdemonstration

.25

Early

Parts

Attention hints

Total before reference-frame hint

Reference-frame hint

Total in imagery

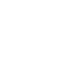

Drawing

.35

$$
.30
$$

$$
.05
$$

.05

.10 control, supporting the findings of Chambers and Reisberg (1985), the findings are collapsed across imagery groups.

In the full-version condition, 7 subjects reported duck/rabbit reversals by the time the attention hints were concluded; an additional subject reported a duck/rabbit reversal following the reference-frame hint. An additional 7 subjects (35\%) reported duck/rabbit reversals of their drawings of their image, suggesting that images formed by at least some of the subjects who were unable to reverse in imagery had not become altered so that referenceframe reversals were no longer possible.

These findings contrast markedly with those of Chambers and Reisberg (1985), who found no reversals in the images of 55 subjects across three experiments. Our figure of $40 \%$ duck/rabbit reversals is significantly greater than what would be expected on the basis of Chambers and Reisberg's experiments $(z=12.13, p<.0001) .{ }^{4}$ We suspect that the difference between the two experimental outcomes reflects the fact that the goose/hawk demonstration figure provided the subjects with reversal strategies that were appropriate to the duck/rabbit image. Hence, our findings are also inconsistent with the hypothesis of Finke et al. (1989), who suggested that reversals of images of the duck/rabbit figure depend on autornatic low-level visual processes.

We do not compare the reversals in the parts conditions with those obtained in the full-version condition, because different procedures were employed in the parts conditions than in the full-version condition. We were interested in comparing performance in the good parts condition with performance in the poor parts condition, however. Seven subjects in the good parts condition (35\%) reported duck/rabbit reversals, whereas only 2 subjects $(10 \%)$ in the poor parts condition reported duck/rabbit reversals. The difference between the good parts and poor parts conditions was significant, as predicted $(z=1.89, p<.03)$. This difference between the two parts conditions clearly indicates the importance of component goodness.

The total duck/rabbit reversal proportions in all conditions of Experiment I were significantly greater than expected on the basis of Chambers and Reisberg's (1985) experiments $(2.55 \leq z \leq 12.14$, ps $<.006)$. Some proportion of these reference-frame reversals were prompted by Hyman and Neisser's (1991) explicit reference-frame hint, but $76 \%$ of the duck/rabbit reversals occurred before the explicit hint. In all conditions, the proportion of reversals occurring before the reference-frame hint were significantly greater than was expected on the basis of Chambers and Reisberg's (1985) findings (2.55 $\leq z \leq 10.54$, $p s<.006)$. Thus, our results demonstrate that referenceframe reversals can occur in imagery.

All reversals. Table 1 (bottom half) shows that when all valid reversals were counted, the rate of reversal increased, from $28.3 \%$ overall (collapsing across conditions) to $53.3 \%$. Again, these proportions indicate that images are reversible. When all reversals were examined, the proportions of reversals in the two parts groups did not differ statistically $(z=1.29, p<.10)$. 


\section{EXPERIMENT 2}

Contrary to the findings of Chambers and Reisberg (1985), and to the proposal of Finke et al. (1989), Experiment 1 showed that both reconstruals and reference-frame realignments can occur for images of the duck/rabbit figure. Furthermore, as predicted, reference-frame realignments were less likely to occur in images assembled from poor parts, as opposed to those constructed from good parts. Although there was a trend in the same direction when all reconstruals were counted as well as referenceframe realignments, the difference between the parts conditions was not statistically reliable. However, the differences between conditions may be related to variables other than those that are critical to shape recognition. For example, subjects in the parts conditions may have failed to correctly synthesize their images. Moreover, research by Palmer (1977) suggests that this failure may have been particularly severe for the subjects who constructed their images from poor parts (although note that the goodness of Palmer's parts was defined with respect to the connectedness of the segments constituting each part, a variable that is irrelevant in our studies).

In Experiment 2, we attempted to improve the quality of the subjects' synthesized images by presenting the parts against a background grid that specified their relative locations. Moreover, as in the study by Chambers and Reisberg (1985), we increased the demands placed on all subjects for imaginal fidelity. First, subjects in the parts conditions, as well as the full-version condition, were warned that they would be asked to draw their images. In addition, we used the glasses/barbells figure from Carmichael, Hogan, and Walter (1932; see Figure 1) to warn subjects in the full-version condition not to alter their images in accordance with their initial interpretation. (Chambers \& Reisberg [1985], who had used this demonstration for the same purposes, had found that their results were unaffected by its presence vs. absence.)

In Experiment 2, we eliminated the goose/hawk figure from the set of demonstration figures and used only demonstration figures that had been used by Chambers and Reisberg (1985). If we were correct in claiming that the duck/rabbit reversals that were obtained prior to the reference-frame hint in Experiment 1 were due to the implicit suggestion for reference-frame reversal supplied by the goose/hawk figure, and not to experimenter bias or to subject sample effects, then eliminating the goose/hawk figure ought to have eliminated those reversals, at least for the subjects in the full-version condition, which in other respects was a replication of one of Chambers and Reisberg's experiments.

\section{Method}

Subjects. The subjects for this experiment were 48 freshman or sophomore students at the University of Arizona, who had never taken any psychology courses. They were paid $\$ 5.00$ for their participation. The subjects were randomly assigned to one of three experimental groups and were tested individually. In view of the results of Experiment 1, subjects were not classified according to their im- agery ability in this experiment or in the remaining studies reported in this paper.

Procedure. At the beginning of the session, all subjects were first shown black-and-white line drawings of the Necker cube, the Rubin vase/faces stimulus, and the Mach book (Figures 2A-2C), in order to acquaint them with ambiguous and reversible figures. The order of presentation of these demonstration figures was counterbalanced.

Figure 2D depicts the grid against which the good and poor parts of the duck/rabbit figure were presented to the subjects in the parts conditions. In this experiment, the " $T$ " intersections and " $X$ " marks used as connection markers in Experiment 1 were replaced with red and blue dots placed at the ends of the part segments in order to avoid any unnecessary structural encoding in the assembly of the figures in the parts conditions. The grid was not used in the full-version condition.

The procedure for this experiment was essentially the same as that for Experiment 1, with the following changes.

Full version. Prior to viewing the duck/rabbit figure, the subjects in the full-version condition $(n=14)$ were shown a blackand-white line drawing of the eyeglass/barbell figure from Carmichael et al. (1932). This demonstration was used to encourage the subjects to remember the duck/rabbit figure exactly as it appeared. The subjects then viewed the full version of the duck/rabbit figure (Figure 1A) for $5 \mathrm{sec} .^{5}$ From then on, the procedure was the same as that in Experiment 1, except that if subjects failed to report duck/rabbit reversals during the series of attention hints, these hints were repeated before the reference-frame hint was given. In addition, if subjects failed to report duck/rabbit reversals in their drawings, we repeated the attention hints while they viewed their drawings, as Chambers and Reisberg (1985) had done. The fullversion condition was a replication of Chambers and Reisberg's Experiment 2.

Good and poor parts versions. Prior to viewing the experimental stimuli, subjects in the parts conditions ( $n=17 /$ group) were shown a blank grid, and they were informed that the purpose of the grid was only to assist them in locating each part relative to the others and that it need not be remembered. They were told that they would be provided with a blank grid during the drawing phase of the procedure. After viewing the series of three parts, and consolidating their mental images, the subjects in the parts conditions were asked the early questions, followed by the parts questions. In an effort to maximize the likelihood of obtaining reversals prior to the reference-frame hint, the subjects were asked to attend to each of the parts again to see whether a reversal of a part could occasion a figural reversal. Next, the chef/dog example was presented, as it was in the full-version condition. From this point on, the observers in the parts conditions were treated just as were the observers in the full-version condition.

\section{Results and Discussion}

Duck/rabbit reversals. Table 2 (top half) shows the duck/rabbit reversals (reference-frame realignments) obtained in Experiment 2.

In the full-version condition, $43 \%$ of the subjects reported duck/rabbit reversals in response to the referenceframe hint. None of the subjects in the full-version condition reported a duck/rabbit reversal prior to the reference-frame hint. This pattern of results is consistent with those of Chambers and Reisberg (1985), Reisberg and Chambers (in press), and Hyman and Neisser (1991); without the strategy suggested by the goose/hawk figure, subjects did not report a duck/rabbit reversal until they were given an explicit reference-frame hint.

In the parts conditions, $30 \%$ of the subjects in the good parts condition and $10 \%$ of the subjects in the poor parts con- 
Table 2

Imagery Reversals Reported in Experiment 2

\begin{tabular}{cccc}
\hline & \multicolumn{3}{c}{ Condition } \\
\cline { 2 - 4 } & Full & Good & Poor \\
Questions & Version & Parts & Parts \\
\hline
\end{tabular}

Duck/Rabbit Reversals

(Reference-Frame Realignments)

\begin{tabular}{|c|c|c|c|}
\hline $\begin{array}{l}\text { Early } \\
\text { Parts } \\
\text { Postdemonstration } \\
\text { Attention hints } \\
\end{array}$ & $\begin{array}{l}.00 \\
.00 \\
\end{array}$ & $\begin{array}{l}.06 \\
.12 \\
.12 \\
.00 \\
\end{array}$ & $\begin{array}{l}.00 \\
.00 \\
.06 \\
.06 \\
\end{array}$ \\
\hline Total before reference-frame hint & .00 & .30 & .12 \\
\hline Reference-frame hint & .43 & .29 & .12 \\
\hline Total in imagery & .43 & .59 & .24 \\
\hline Drawing & .36 & .12 & .06 \\
\hline \multicolumn{4}{|c|}{ All Reversals } \\
\hline Early & & .41 & .35 \\
\hline Parts & & .12 & .06 \\
\hline Postdemonstration & .00 & .06 & .12 \\
\hline Attention hints & .36 & .06 & .06 \\
\hline Total before reference-frame hint & .36 & .65 & .53 \\
\hline Reference-frame hint & .57 & .18 & .00 \\
\hline Total in imagery & .93 & .83 & .53 \\
\hline Drawing & .07 & .06 & .12 \\
\hline
\end{tabular}

dition reported duck/rabbit reversals before the referenceframe hint. Both of these proportions were significantly more likely than was expected on the basis of Chambers and Reisberg's (1985) experiments $(z \geq 2.94, p s<.002)$. The fact that duck/rabbit reversals were obtained only in the parts groups prior to the reference-frame hint is intriguing, especially in light of Biederman's (1987) proposal that the representational components accessed by the parts of a shape are reference-frame free.

Following the reference-frame hint, 5 more subjects in the good parts condition and 2 more subjects in the poor parts condition reported a duck/rabbit reversal. Thus, $59 \%$ of the subjects in the good parts condition, but only $24 \%$ of those in the poor parts condition, reported duck/rabbit reversals. The difference between the duck/rabbit reversals reported by subjects in the good parts and poor parts conditions was significant $(z=2.07, p<.02)$.

All reversals. As in Experiment 1, the subjects offered many interpretations of their images other than, or in addition to, ducks and rabbits. Table 2 (bottom half) shows that when reconstruals are counted in addition to duck/rabbit reversals, the rate of reversal increased, from $42 \%$ overall (collapsing across conditions) to $76 \%$. In all conditions, the reversals reported were significantly greater than would be expected on the basis of Chambers and Reisberg's (1985) experiments, even before the reference-frame hint $(9.09 \leq z \leq 24.33$, ps $<.0001)$. When reversals obtained before the reference-frame hint are examined, it can be seen that the proportions of all reversals were significantly greater than the proportions of duck/rabbit reversals in all conditions $(2.04 \leq z \leq 3.50, p s<.05)$. The increase in total reversals was significant only in the full-version condition $(z=2.83, p<.005)$, however. When all reversals were counted, the difference between the good parts and poor parts conditions was only marginally significant $(z=1.54, p<.07)$.

Evaluation of drawings. One purpose of Experiment 2 was to improve the quality of the images constructed in the parts conditions, and through the use of the grid, to permit subjects to construct images of comparable quality out of good and poor parts. Although the quality of the images cannot be determined directly, because imagery is essentially private, some estimate of their quality can be obtained from evaluations of the drawings produced by the subjects (cf. Chambers \& Reisberg, 1985).

Four psychology graduate students at the University of Arizona, who were unaware of the hypotheses being tested in this line of research, were asked to evaluate all the drawings produced by the subjects in the parts conditions of Experiments 1 and 2 who failed to report a duck/rabbit reversal in imagery. ${ }^{6}$ Experiment 1 provided 13 drawings from the good parts condition and 18 from the poor parts condition (three drawings in each condition had supported a reversal during the drawing phase of the experiment); Experiment 2 provided 6 drawings from the good parts condition and 10 from the poor parts condition (one drawing in each condition had supported a reversal during the drawing phase). In order to anchor the judgments, the full version of the duck/rabbit figure (Figure 1A) was added to the set, to make a total of 48 stimuli.

The judges were given a brief explanation of reversibility in general, and of the duck/rabbit figure in particular. They were then asked to rate the degree to which each of the 48 drawings was reversible. The ratings were made on a 5-point scale according to the Q-sort procedure developed by Stephenson (1953), in which each rater is forced to distribute his or her ratings normally (for reviews, see Brown, 1986; McKeown \& Thomas, 1988). The Q-sort technique is generally recognized as a highly efficient way of gathering rather precise comparative ratings of objects (Nunnally, 1978). By stipulating the center, dispersion, and shape of the distribution in advance, it forces all raters to use a common metric and permits analysis by standard parametric statistics. For the purposes of this experiment, a normal distribution was defined as one having 6 drawings in each of the lowest (1) and highest (5) rating categories, 10 drawings in each of the adjacent categories ( 2 and 4 ), and 16 drawings in the middle category (3).

The four judges showed substantial interrater agreement in their ratings, as measured by the pairwise correlations among them (average $r=.82$ ). In order to obtain the most reliable estimate of reversibility, the four judges' ratings of each drawing were averaged to produce an aggregate score.

The pooled ratings confirmed our impressions of the drawings. In Experiment 1, the drawings made by the good parts subjects $(M=3.58, S D=0.97)$ received better ratings than did those of the poor parts subjects $[M=$ $2.64, S D=1.14, t(29)=2.41, p<.05]$; however, in 
Experiment 2, there were no differences between the two groups (good parts, $M=2.71, S D=1.23$; poor parts, $M=2.88, S D=0.65 ; t<1$ ).

In order to exclude the possibility that the failure to discriminate between the drawings made by good parts and poor parts subjects in Experiment 2 was an artifact of forcing judges to distribute their ratings normally across the two experiments, the ratings of the 16 drawings from Experiment 2 were repeated. Four new graduate student judges received the instructions that had been given to the original group, except that their quasinormal distribution was adjusted for the number of Experiment 2 drawings only (one drawing in each of Categories 1 and 5, three each in Categories 2 and 4, and eight in Category 3). These judges were unable to distinguish the drawings of the good parts and poor parts groups $(t<1)$.

Thus, either warning the subjects about the drawing requirement or displaying the parts against a grid had the intended effect of enabling subjects to assemble their images correctly. Accordingly, the fact that the subjects in the poor parts group reported fewer reversals cannot be explained easily by confounding differences in the quality of the assembled image.

\section{Discussion of Experiments 1 and 2}

Experiments 1 and 2, taken together, show that referenceframe realignments can occur in imagery. The pattern of results across the two experiments does indicate that duck/rabbit reversals (reference-frame realignments) of the full version of the duck/rabbit image are unlikely to occur uniess they are cued by either an explicit (e.g., the reference-frame hint) or implicit (e.g., the goose/hawk demonstration figure) suggestion. On the other hand, the fact that such reversals occurred at all refutes the proposal of Finke et al. (1989) that reference-frame realignments require either a holistic style of processing not available in mental imagery, or a low-level perceptual process that does not cross some perception/cognition barrier.

In addition, Experiments 1 and 2 show that reconstruals of images are common. Regardless of the demonstration figures used, $30 \%-65 \%$ of the subjects reconstrued their images prior to the explicit reference-frame hint. Thus, Experiments 1 and 2 suggest that reconstruals of images are more common than reference-frame realignments and may occur regardless of experimental conditions. Of course, these conclusions must be qualified by the fact that they rely on comparisons between experiments that differed in a number of respects. Therefore, in Experiment 3 we examined the influence of demonstration figure within a single experiment.

\section{EXPERIMENT 3}

Because the goodness of parts is irrelevant to the question of the effects of demonstration figures, we examined reversals obtained in the full-version condition only. The subjects did not view any demonstration figures before viewing the duck/rabbit figure and forming their images.
Consequently, experience with the demonstration figure could not change the way in which the stimuli were perceived. Following image formation, we showed the subjects (1) the goose/hawk figure (Figure 1C), (2) the chef/dog figure (Figure 1B), (3) the Rubin figure/ground stimulus (Figure 2B), or (4) no demonstration figure. We predicted that observers who viewed the goose/hawk demonstration figure would report more reference-frame reversals than would observers who did not see a demonstration figure, or observers who viewed the Rubin figure, which suggests a strategy (switching figure and ground) that is inappropriate for reversing the duck/rabbit figure. Because reversal of the chef/dog figure entails referenceframe realignment as well as part reconstrual, its presence as a demonstration figure might induce some subjects to use the correct strategy in reversing their images of the duck/rabbit. Remember, however, that Chambers and Reisberg (1985) had used the chef/dog figure as a demonstration figure and had obtained no reversals whatsoever.

In Experiment 3, we asked the subjects to describe the parts of each interpretation they named with respect to the parts of their initial interpretation (i.e., either the duck or the rabbit). This procedure allowed us to be sure that the valid interpretations encompassed the entire image. It also allowed us to determine the reference frames for each interpretation.

\section{Method}

Subjects. The subjects were 116 students at the University of Arizona who were paid $\$ 5.00$ for their participation. None of the subjects had taken a psychology course.

Procedure. The subjects were told that they were going to be asked to form a mental image of a picture, to remember it while they engaged in other tasks, and then to draw their image. The Carmichael et al. (1932) glasses/barbells demonstration was used to warn subjects not to alter their images in accordance with their interpretation. The subjects viewed the full version of the Jastrow duck/rabbit figure for $5 \mathrm{sec}$. Half of the subjects saw the figure facing to the left; the other half saw it facing to the right. After the figure was removed, the subjects were given as much time as they needed to memorize their images. When subjects indicated that they were ready to go on, the experimenter asked them to report what the image looked like. The data from the subjects who reported both duck and rabbit interpretations at this point were eliminated from further analysis. ${ }^{7}$ Next, the experimenter showed subjects in the experimental conditions ( $n=29$ /group) the goose/hawk figure, the chef/dog figure, or the Rubin vase/faces figure. All subjects perceived a reversal of the demonstration figure and pointed out the parts of the different interpretations to the experimenter. The subjects in the control condition $(n=29)$ were asked to count aloud backwards from 500 by units of either 1 or 3 for durations that were matched to the durations that the subjects in the experimental conditions spent viewing the demonstration figure.

Next, subjects in all conditions were given the series of questions and hints given to the subjects in the full-version condition of Experiment 2, with one exception. We employed two types of explicit reference-frame hints in this experiment, both of which had been used by Hyman and Neisser (1991). The first explicit hint contained no reference to animals; we simply asked the subjects to "consider the front of the thing you were seeing as the back of something else." We will refer to this hint as the abstract reference-frame hint. Subjects who failed to report a duck/rabbit reversal following the abstract reference-frame hint were given a second hint, con- 
taining category information as well as reference-frame information. As in Experiment 1, they were asked to consider the front of the head of the animal that they had just seen as the back of the head of some other animal. Hyman and Neisser had found that this reference-frame-plus-category hint was more effective than the abstract reference-frame hint in prompting a reversal. We will refer to this hint as the conceptual reference-frame hint.

Following these questions, the subjects were asked to draw the image. We clarified any uncertainties about the interpretations that the subjects had named earlier by asking them to use their drawings to point out the parts of the interpretations they named, as well as the front/back and top/bottom directions.

All subjects viewed the duck/rabbit figure again at the end of the experiment, and we ascertained that they were able to reverse between duck and rabbit interpretations of the picture; the data from 1 subject who was unable to see both interpretations of the picture was not analyzed. In addition, all subjects were asked whether they had ever seen the Jastrow (1990) duck/rabbit picture before; the data from 1 subject who reported that he had seen the duck/rabbit picture before was not analyzed.

\section{Results and Discussion}

Duck/rabbit reversals. As can be seen in Table 3 (top part), some of the subjects in each group reported duck/ rabbit reversals before the explicit reference-frame hint. The proportions of reversals prior to the reference-frame hint were significantly greater than was expected on the basis of Chambers and Reisberg's (1985) experiments in the goose/hawk, chef/dog, and no-demonstration-figure conditions $(3.07 \leq z \leq 12.69, p<.001)$, but not in the figure/ground condition $(z=1.53, p<.07)$. In addition, the proportion of subjects reporting duck/rabbit reversals prior to the reference-frame hint was greater in the goose/ hawk condition than in the other conditions ( $z \mathrm{~s} \geq 2.27$, ps $<.02$ ), as predicted.

Subjects in all conditions reported additional duck/rabbit reversals following the two reference-frame hints, but the increase in reversals was statistically significant only in the figure/ground demonstration figure condition $(z=$ $2.15, p<.032$ ). Despite the increase in duck/rabbit reversals following the reference-frame hints, the total proportion of reversals remained larger among subjects who had viewed the goose/hawk figure than among subjects in any of the other three conditions $(z \geq 1.94, p \mathrm{~s}<.03)$. Overall, we did not find, as Hyman and Neisser (1991) had, that the conceptual reference-frame hint prompted more duck/rabbit reversals than did the abstract referenceframe hint $(z<1)$.

All reference-frame realiggmments. Subjects in all groups reported other reversals entailing reference-frame realignment in addition to duck/rabbit reversals (i.e., other reversals that entailed a change in the front/back and/or top/ bottom coordinates of the imagined shape). Table 3 (middle) shows all reference-frame realignments, collapsed across both duck/rabbit and other reference-frame realignments. When the total proportions of all reference-frame realignments in imagery were examined, reversal probabilities were greater in the chef/dog condition than they were when only duck/rabbit reversals were counted $(z=$ $3.22, p s<.002$ ). There were similar trends in the figure/ ground condition $(z=1.94)$ and in the no-demonstrationfigure condition $(z=1.90, p \mathrm{~s}<.06)$.

Table 3

Duck/Rabbit Reversals, All Reference-Frame Reversals, and All Reversals Reported by Subjects in Experiment 3

\begin{tabular}{|c|c|c|c|c|}
\hline Questions & $\begin{array}{l}\text { Goose/ } \\
\text { Hawk }\end{array}$ & $\begin{array}{l}\text { Chef/ } \\
\text { Dog }\end{array}$ & $\begin{array}{l}\text { Figure/ } \\
\text { Ground } \\
\end{array}$ & None \\
\hline \multicolumn{5}{|c|}{ Duck/Rabbit Reversals } \\
\hline $\begin{array}{l}\text { Postdemonstration } \\
\text { Attention hints }\end{array}$ & $\begin{array}{r}.21 \\
.14 \\
\end{array}$ & $\begin{array}{l}.03 \\
.07 \\
\end{array}$ & $\begin{array}{l}.03 \\
.03\end{array}$ & $\begin{array}{l}.00 \\
.10 \\
\end{array}$ \\
\hline Total before reference-frame hint & .35 & .10 & .06 & .10 \\
\hline $\begin{array}{l}\text { Abstract reference-frame hint } \\
\text { Conceptual reference-frame hint }\end{array}$ & $\begin{array}{l}.03 \\
.14 \\
\end{array}$ & $\begin{array}{l}.10 \\
.03\end{array}$ & $\begin{array}{l}.14 \\
.07 \\
\end{array}$ & $\begin{array}{l}.07 \\
.07 \\
\end{array}$ \\
\hline Total in imagery & .52 & .23 & .27 & .24 \\
\hline Drawing & .14 & .38 & .28 & .31 \\
\hline \multicolumn{5}{|c|}{ All Reference-Frame Realignments } \\
\hline $\begin{array}{l}\text { Postdemonstration } \\
\text { Attention hints }\end{array}$ & $\begin{array}{l}.21 \\
.17 \\
\end{array}$ & $\begin{array}{l}.10 \\
.17 \\
\end{array}$ & $\begin{array}{l}.14 \\
.10 \\
\end{array}$ & $\begin{array}{l}.14 \\
.07 \\
\end{array}$ \\
\hline Total before reference-frame hint & .38 & .27 & .24 & .21 \\
\hline $\begin{array}{l}\text { Abstract reference-frame hint } \\
\text { Conceptual reference-frame hint }\end{array}$ & $\begin{array}{l}.14 \\
.14 \\
\end{array}$ & $\begin{array}{l}.31 \\
.07 \\
\end{array}$ & $\begin{array}{l}.14 \\
.14 \\
\end{array}$ & $\begin{array}{l}.17 \\
.10 \\
\end{array}$ \\
\hline Total in imagery & .66 & .65 & .52 & .48 \\
\hline \multicolumn{5}{|c|}{ All Reversals } \\
\hline $\begin{array}{l}\text { Postdemonstration } \\
\text { Attention hints } \\
\end{array}$ & $\begin{array}{l}.45 \\
.24 \\
\end{array}$ & $\begin{array}{l}.41 \\
.28\end{array}$ & $\begin{array}{l}.41 \\
.24 \\
\end{array}$ & $\begin{array}{l}.48 \\
.21 \\
\end{array}$ \\
\hline Total before reference-frame hint & .69 & .69 & .65 & .69 \\
\hline $\begin{array}{l}\text { Abstract reference-frame hint } \\
\text { Conceptual reference-frame hint }\end{array}$ & $\begin{array}{l}.21 \\
.03 \\
\end{array}$ & .10 & $\begin{array}{l}.07 \\
.14 \\
\end{array}$ & $\begin{array}{l}.17 \\
.03 \\
\end{array}$ \\
\hline Total in imagery & .93 & .83 & .86 & .89 \\
\hline
\end{tabular}


Contrary to Hyman and Neisser's (1991) findings, we once again found that the conceptual reference-frame hint was no more effective than the abstract reference-frame hint $(z<1)$. Indeed, in the chef/dog condition, the abstract reference-frame hint was more effective in prompting reference-frame realignments $(z=2.32, p<.03)$.

It is notable that in both the figure/ground condition and the no-demonstration-figure condition, approximately half of the additional reference-frame realignments entailed a $90^{\circ}$ change in the top/bottom and/or front/back coordinates of the imagined shape, rather than a $180^{\circ}$ change. In the chef/dog condition, only one of the additional reference-frame realignments entailed a $90^{\circ}$ rather than a $180^{\circ}$ change; and in the goose/hawk condition, none of the additional reference-frame realignments entailed a $90^{\circ}$ change.

When all reference-frame realignments are considered, the differences among the conditions disappear ( $z s \leq 1.38$ ).

All reversals. All reversals, including reconstruals as well as all reference-frame realignments, are shown in Table 3 (bottom). Once again, it is clear that reconstruals occur commonly in imagery, regardless of the experimental conditions. When reconstruals are counted, as well as reference-frame realignments, the likelihood of reversal prior to the reference-frame hints increases significantly in all conditions $(2.36 \leq z \leq 3.67, p s<.02)$. When reversals occurring after the reference-frame hint are included as well, reversals are increased significantly by counting reconstruals as well as reference-frame realignments in all but the chef/dog condition $(z s \geq 2.54, p s$ $<.02$; for the chef/dog condition, $z=1.56$ ). There were no differences between conditions in the total reversals when all reversals were counted.

Experiment 3 demonstrates that without the misleading strategies suggested by the Necker cube, the Schroeder staircase, and the Mach book-indeed, without the use of any demonstration figures prior to image formationreference-frame realignments are clearly possible in mental imagery. At the same time, the results of Experiment 3 support the hypothesis that the type of demonstration figures used is critical to the likelihood of obtaining a duck/rabbit reversal, both before and after the explicit reference-frame hint. More duck/rabbit reversals were obtained in the goose/hawk condition than in the other conditions, both before and after the reference-frame hint. In addition, our finding that significantly fewer duck/rabbit reversals were obtained in the figure/ground condition than in the other conditions prior to the reference-frame hint indicates that the subjects in the figure/ground condition may have employed strategies that were inappropriate to reversing the duck/rabbit figure. When the criteria for reversal were broadened to include all reference-frame realignments, more than half of the subjects, $58 \%$, reversed their images, and the differences between the conditions disappeared. When the criteria for reversal were broadened further to include reconstruals as well, $88 \%$ of the subjects were able to reverse their images. Even in the condition in which subjects had no experience with a demonstration figure, $10 \%$ of the subjects reported duck/rabbit reversals, $21 \%$ reported reversals that entailed some type of reference-frame realignment, and $69 \%$ reported reversals that entailed part reconstrual before the reference-frame hint was given.

\section{EXPERIMENT 4}

The valid interpretations of the duck/rabbit figure (which were scored as reconstruals or as other reference-frame realignments), although structurally consistent with the figure, were clearly not the designated alternatives for the duck/rabbit figure. This raises the question of whether reversals of mental images necessarily differ in nature from reversals of pictures. To examine that question, we conducted another experiment in which we used a figure whose two dominant interpretations require reconstrual only, without any reference-frame realignment: Fisher's (1976) snail/ elephant figure, shown in Figure 4A. ${ }^{8}$ The front/back and top/bottom specifications for both the snail and the elephant are shown in Figure 4A. If the reversals that are pervasive in mental imagery can be similar to perceptual reversals, then reversal between the two designated interpretations of the snail/elephant should occur commonly in mental imagery. Moreover, if reversals of images can occur spontaneously, without explicit prompting provided by hints, or without implicit prompting provided by demonstration figures, then reversals of mental images of the snail/ elephant should occur under conditions in which observers are neither given special instructions about ambiguity nor shown any demonstration figures.

As in Experiments 1 and 2, we examined performance with both a full version of the snail/elephant figure and versions constructed from good parts and from poor parts. This experiment also included a control condition, modeled after one employed by Finke et al. (1989, Experiment 3), which was designed to assess whether the reversals in imagery had been anticipated by reversals of the parts while they were being viewed. After viewing each of the first two parts, observers in the control condition were asked to state what they thought the full figure might be once assembled. Reversals of the whole image that were anticipated in responses to these questions were not scored as imagery reversals.

\section{Method}

Subjects. The subjects in this experiment were 60 undergraduates at the University of Arizona who were paid $\$ \mathbf{5 . 0 0}$ for their participation; none had taken a psychology course.

Stimulus and Materials. Our stimulus was a simpler version of the snail/elephant figure (Figure 4B), which we thought might be easier to hold in imagery than the original version. We tested whether our simplified version still supported snail/elephant reversals by showing the figure for 2 min to 43 observers who were told that the picture was ambiguous and were asked to indicate what the shape depicted, listing as many interpretations as they felt the figure supported. This procedure also served as a means of identifying other valid interpretations a priori. Interpretations offered by more than $10 \%$ of these perceiving subjects were designated as valid interpretations for the image. As can be seen in Table 4 (top), perceiving subjects reported that our simplified 


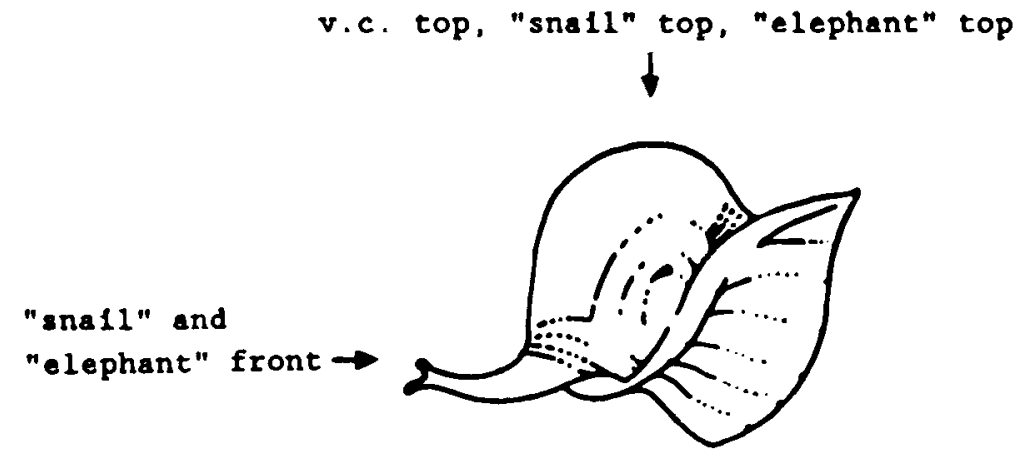

a.

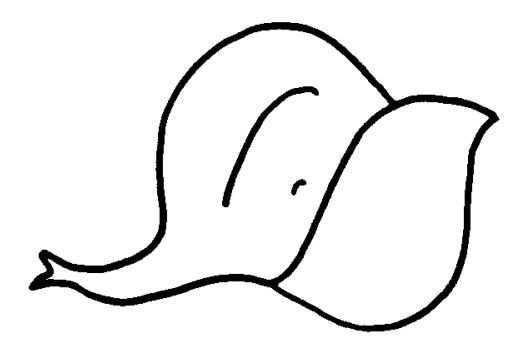

b.

Figure 4. (A) Fisher's snail/elephant figure with reference-frame specifications indicated for both interpretations. (B) Our simplified version of the snail/elephant figure.

Table 4

Proportions of Perceiving Subjects Reporting the Valid Interpretations for the Snail/Elephant and the Proportions of Subjects Reversing Between Two Valid Interpretations in the Full-Version Condition of Experiment 4

\begin{tabular}{lcc}
\hline \multicolumn{1}{c}{ Interpretations } & & $\begin{array}{c}\text { Proportions } \\
\text { of Subjects }\end{array}$ \\
\cline { 2 - 3 } Elephant & Valid & \\
Snail & & .73 \\
Bird & & .64 \\
Sea shell & .31 \\
Leaf & & .20 \\
Flower & & .20 \\
Helmet/hat & & .16 \\
& Reversals & .14 \\
Snail/elephant & & \\
Elephant/snail & & .33 \\
Snail/leaf & .17 \\
Snail/bird & .17 \\
Elephant/flower & .08 \\
Total reversals in imagery & .08 \\
\hline
\end{tabular}

snail/elephant figure depicted both a snail and an elephant, and there were a number of other valid interpretations as well. We regarded all these figures as sharing their top/bottom and front/back specifications with the snail and elephant interpretations.

Two additional versions of Figure $4 B$ were designed, as shown in Figures 5A and 5B; Figure 5A was segmented at the minima of curvature, Figure 5B was segmented at contour regions between the minima of curvature. The parts of these two versions formed good and poor parts, respectively. We corroborated our intuitions that these were good and poor parts in a pilot study in which we showed 26 observers the full version of the simplified snail/elephant figure along with both sets of parts. Observers were asked to decide which set of parts was most "natural," and to rate the naturalness of the parts in both sets on a 1-7 scale, with 1 indicating very natural, and 7 indicating very unnatural. We found that $73 \%$ of the observers chose the good parts as being the most natural. In addition, observers rated the good parts as more natural than the poor parts [3.46 vs. $4.69 ; t(25)=2.15, p<.05$ ]

Procedure. The subjects served in one of five conditions. The subjects in the full-version condition viewed Figure 4B for $5 \mathrm{sec}$. As in the full-version condition of Experiments 1 and 2, they were asked to form and maintain an accurate mental image of the figure so that they could later produce a drawing of it. Once they had consolidated the image, they were asked to identify it. Next, they were informed that the image was ambiguous, and were asked whether it depicted anything else. The subjects were then given attention hints and parts hints. Parts hints 

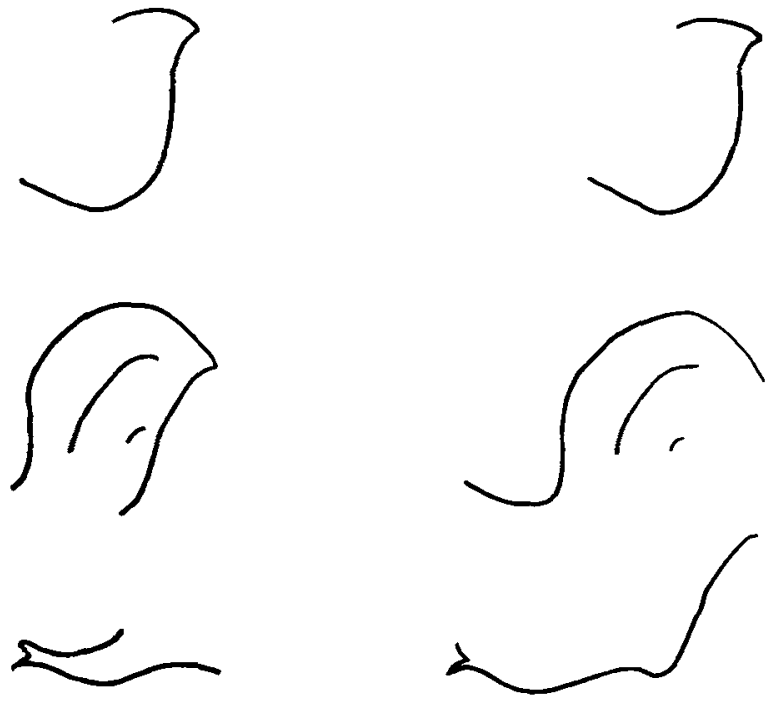
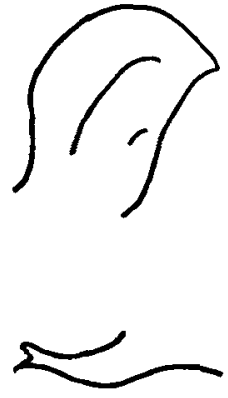

a. b.
Figure 5. The parts shown to subjects in Experiment 4. (A) Parts shown in the good parts condition. (B) Parts shown in the poor parts condition. Connection markers are not shown.

referred to parts of the initial interpretation that they had named (e.g., the trunk of an elephant, the shell of a snail, the head of a bird).

The subjects in the parts conditions served in either the experimental group or the control group. Half the subjects in both the experimental and the control groups participated in a good parts condition and half participated in a poor parts condition. The procedure for showing the parts was the same as that in the previous experiments, except that the connection markers were red and blue hatch marks. The parts were presented in an order corresponding to either top/bottom or bottom/top order, as shown in Figure 5. Affer they had viewed each part, the subjects in the conirol group were asked what they thought the whole figure was going to be. Their answers to these questions were used later to exclude any reversals that had been anticipated immediately after presentation of a single part. After the subjects in the parts conditions had formed the whole image, they received the same treatment as subjects in the full-version condition had following the consolidation of their images.

Following the question period, all subjects were asked to draw their images and to try to reverse their drawings. The subjects viewed no demonstration figures before viewing the figures or during the question period.

\section{Results and Discussion}

Full-version condition. As can be seen in Table 4 (bottom), $83 \%$ of the subjects alternated between at least two valid interpretations of their images of the snail/elephant figure; the most common of these were between snail and elephant, reported by $33.3 \%$ of the subjects. The proportion of subjects reporting valid reversals was significantly greater than was predicted on the basis of Chambers and Reisberg's (1985) findings $(z=21.28, p<.0001)$.

Parts conditions. Table 5 shows the proportion of subjects in the parts conditions offering various reversals of their images of the snail/elephant. In the experimental group, 5 subjects in the good parts group, but no subjects in the poor parts group, reported valid reversals of their images. This difference between groups was significant $(z=2.51, p<.01)$. In the control group, the pro- portion of subjects who reversed the image was larger in the good parts condition than in the poor parts condition (66\% vs. $25 \% ; z=2.01, p<.03$ ). Of these reversals, three offered by subjects in the good parts condition and two offered by subjects in the poor parts condition were judged to have been anticipated by a reversal of a part while it was being viewed. Eliminating these reversals reduced the proportions of control subjects reporting reversals to $42 \%$ in the good parts condition and $8 \%$ in the poor parts condition, but the difference between the parts conditions remained statistically significant $(z=1.88$, $p<.04$ ). In any event, the fact that so many reversals occurred, even in the absence of an explicit suggestion, is consistent with the results of Experiments 1-3, and it is inconsistent with the findings of Chambers and Reisberg (1985).

\section{GENERAL DISCUSSION}

Taken together, these experiments demonstrate convincingly that reversals occur commonly in mental imagery, even when no hints or strategies are provided. Hence, the structural and denotative aspects of images of classic reversible figures can be dissociated in imagery. Images can be ambiguous, contrary to the claims made by Chambers and Reisberg (1985; Reisberg \& Chambers, 1991). On the other hand, these experiments indicate that the structural aspects of an image may be separated less easily from the reference frame in which they are specified than from the interpretation assigned within that reference frame. Our experiments show that this dissociation between reconstruals and reference-frame realignments is due neither to a distinction between the visual processes that occur at an automatic low level and those that occur at a higher level and that might be open to regulation by conscious processes, nor to the necessity of perceiving holistically, as suggested by Finke et al. (1989).

Table 5

Valid Reversals of the Snail/Elephant Reported by Subjects in the Experimental and Control Parts Conditions of Experiment 4

\begin{tabular}{|c|c|c|c|c|}
\hline \multirow[b]{3}{*}{ Interpretations } & \multicolumn{4}{|c|}{ Group } \\
\hline & \multicolumn{2}{|c|}{ Experimental } & \multicolumn{2}{|c|}{ Control } \\
\hline & $\begin{array}{l}\text { Good } \\
\text { Parts }\end{array}$ & $\begin{array}{l}\text { Poor } \\
\text { Parts }\end{array}$ & $\begin{array}{l}\text { Good } \\
\text { Parts } \\
\end{array}$ & $\begin{array}{l}\text { Poor } \\
\text { Parts }\end{array}$ \\
\hline Snail/elephant & .17 & .00 & $.25(.17)$ & $.08(.00)$ \\
\hline Snail/flower & 17 &.$\infty$ & .00 & .00 \\
\hline Snail/bird & .00 & .00 & .08 & .00 \\
\hline Elephant/hat & .08 & .00 & .00 & .00 \\
\hline Elephant/sea shell & .00 & .00 & $.08(.00)$ & .00 \\
\hline Elephant/bird & .00 & .00 & .17 & $.08(.00)$ \\
\hline Elephant/flower & .00 & .00 & $.08(.00)$ & .00 \\
\hline Ser shell/flower & .00 & .00 & .00 & .08 \\
\hline Total & .42 & .00 & $.66(.42)$ & $.25(.08)$ \\
\hline Drawing & .08 & .00 & .17 & .00 \\
\hline
\end{tabular}

Note-Proportions in parentheses represent only those reversals that were not anticipated by control subjects' guesses about what the final configuration would denote. 
Recently, Reisberg and Chambers (1991) have demonstrated that mental images tend to retain their initial reference frames, even when rotated, at least under conditions in which contextual "setting" figures are used to bias the interpretation of the image. On the basis of these demonstrations, Reisberg and Chambers have argued that an image "has no existence independent of our understanding of it." One of the attributes that they subsume under the notion of "understanding an image" is the "orientation" of the image (what we have called the reference frame). They propose that the orientation of an image governs memory access. But note that Reisberg and Chambers do not argue that the reference frame governs only initial access, or that it governs access to structural categories of shapes defined by their reference frames, as we do below. They argue that the reference frame assigned to a shape governs memory access to a single, unambiguous interpretation. Remember that in their view, reversals reported following explicit reference-frame hints depend on the substitution of a new image, described in a new reference frame, for the original image. They stress that "images are entirely unambiguous in what they depict." This view is simply not consistent with our findings, repeatedly demonstrated, that both reference-frame realignments and reconstruals can occur in imagery, even without the use of explicit or implicit hints.

\section{Functional Subsets of Memory Images}

We take our results to be consistent with the idea that representations in memory may be organized into functional subsets sharing similar reference-frame specifications. Others have proposed that an access path into shape representations might be determined by the axis of the coarsest generalized cone that can be fitted to the shape (Marr, 1977; Marr \& Nishihara, 1978), or that different types of components (e.g., rectilinear vs. curvilinear components) might be organized into different subsystems (Pinker, 1985). However, no previous authors have suggested that representational sets might be defined by the assignment of the top/bottom or front/back directions within a shape.

In our view, reversals in both imagery and perception reveal information about aspects of the process of perceptual recognition. We argue that in both recognition and reversal, there exists a stage in which a structural description of a shape is not connected to an interpretation. (The connection may not yet have been made in recognition, whereas it may have been severed in reversal.) We propose that, at this stage, all representations specified in a reference frame similar to that initially assigned to the input shape are searched exhaustively. In the absence of sufficiently good matches in the original set, the search is widened gradually to include representations specified in different reference frames. Thus, representations in memory are accessed in functional subsets according to their reference-frame specifications.
The proposal that the front/back and top/bottom specifications in a reference frame form functional subsets of representations can explain findings in the shape recognition domain as well as in the imagery domain. In particular, a substantial body of evidence now shows that the latency to name disoriented shapes increases incrementally as the disparity between the shape's typical orientation and the presented orientation increases (e.g., Jolicoeur, 1985; 1988; Maki, 1986; Tarr \& Pinker, 1989; see also Mach, 1906/1959; Peterson, Harvey, \& Weidenbacher, 1991; Rock, 1973). Although most investigators take the shape of this function to indicate that a process similar to mental rotation precedes the recognition of disoriented shapes, it is also consistent with a search that spreads in an orderly fashion to different functional subsets in memory.

The functional subsets hypothesis can also account for the discrepancies found between the types of reversals obtained in imagery and in perception, as follows. Suppose that the individual components as arranged in the duck/rabbit figure support a number of alternatives within the original reference-frame set, but that those reconstruals are subverted by the surface details available on a picture that is continually in view. When the picture remains in view, these failures to find a match in the initial reference-frame set precipitate a search through sets of representations that differ more and more from the initial coordinates, until finally a match is found in a set of representations with reversed front/back coordinates, yielding a reversal classified as a reference-frame realignment. In imagery, however, fewer surface details may be present than are present in the picture (Kosslyn, 1980). Consequently, potential reconstruals within the original reference-frame set might not be precluded in imagery. Accordingly, reconstruals would be expected to be more common in imagery than in perception. In addition, other reversals entailing reference-frame realignments would also be possible, as we have found. Further research must decide these issues, but we obtained some support for our hypothesis in an experiment in which we showed different versions of the duck/rabbit figure to different groups of observers and asked them all to list all the objects depicted by the pictures. We found that observers who viewed versions of the Jastrow duck/rabbit in which the eye (and the rabbit's nose in some cases) had been erased were more likely to report certain reconstruals of the image than were observers who viewed the intact duck/rabbit figure (see Peterson, in press, for details).

Our finding that reference-frame realignments are less common in imagery than in perception might be a consequence of the fact that it takes longer to complete a match between a structural description and a representation specified in a reference frame different from that of the input shape (as implied by the naming latency results described above). Within the time frame required for searching through different functional sets of shape rep- 
resentations, the operation of certain processes endemic to imagery might preclude reference-frame reversals. For example, suppose that, as Kosslyn (1980; Kosslyn et al., 1983) has proposed, images must be regenerated periodically. Suppose that image regeneration is normally conducted within the original reference frame in which an image is specified. If the periods of image regeneration fall within the time required to complete the search that culminates in reference-frame realignments, the image regeneration process might often preclude reference-frame realignments in imagery. Hinton's (1979a, 1979b; Hinton \& Parsons, 1981) proposal that images are generated within a viewer-centered reference frame is consistent with this interpretation. Of course, our experiments suggest that observers can intervene in this matching process, thereby causing a reference-frame realignment to occur.

In offering this search interpretation, we do not intend to rule out a role for bottom-up processes in perceptual reversals of shapes like the duck/rabbit. It is conceivable that stimulation-induced fatigue can lead to a redistribution of reference-frame specifications, similar to the redistribution of responses in fatigued motion-detecting units or orientation units. To allow that stimulation-induced fatigue may play a role in perceptual reversals does not imply that its absence precludes reversals, however. Our experiments certainly demonstrate that stimulation-induced fatigue is unnecessary.

\section{Goodness of Parts}

Our experiments revealed that subjects who construed an image from parts delimited by the minima of curvature (good parts) were more likely to report both reversals and reconstruals of their images than were subjects who constructed an image from poor parts. These results are consistent with current theories about how shape contours are partitioned (Hoffman \& Richards, 1985; Marr, 1977) and about the representational components to which the contour parts are mapped (Biederman, 1987). If our good parts map directly onto representational components, they would be expected to support the same interpretations as would the parts extracted from the full version in the perceptual process. Moreover, the difference between the good and poor parts conditions is consistent with Peterson and Weidenbacher's (1987) proposal that images of familiar shapes can be (re)generated more easily than images of unfamiliar shapes.

In addition, these experiments also add a new variable that defines the goodness of the parts of an imagepartitioning at the natural joints of a shape-to the Gestalt variables of proximity and goodness demonstrated by Palmer (1977), and they extend the findings of Reed (1974), who demonstrated that the functional parts of an image are determined by the perceived organization.

\section{Implications for Theories of Imagery}

At a broader theoretical level, the experiments reported here may be viewed in the context of the continuing de- bate over the relationship between perception and imagery. Certainly, if imagery and perception share common mental mechanisms, we would expect visual images and percepts to have a number of properties in common. But images are not pictures, so differences are to be expected as well. And indeed, empirical research has revealed a number of similarities and differences (for comprehensive reviews, see Finke, 1980, 1985, 1989).

The present research identifies further similarities and differences between perception and imagery. On the one hand, it is now clear that mental images of pictures of ducks and rabbits, and snails and elephants (and not just of familiar letters like Js and Ds), can be reversed-just as the corresponding pictures can be. Moreover, the processing of images is affected by the quality of their components, just as the perception of pictures is (Biederman, 1987). And both imagery and perception are influenced by top-down processes, as is reflected in the effects of the particular expectations and strategies employed by the subjects. Whether images are as reversible as pictures is another matter, but the fact of reversibility indicates that perception and imagery share processes that penetrate to the level at which reference frames are established, and before recognition and interpretation occur.

On the other hand, it should be noted that of the various types of reversal, reversals entailing reference-frame realignment appear to be more likely in perception than in imagery. Whether this difference is due to differences in surface details available in percepts and images, or to the fact that images but not percepts must be continually refreshed, or to some other factor as yet unknown, is for future research to determine.

\section{REFERENCES}

Biederman, 1. (1987). Recognition by components: A theory of human image understanding. Psychological Review, 94, 115-147.

Brown, S. R. (1986). Q technique and method. In W. D. Berry \& M. S. Lewis-Beck (Eds.), New tools for social scientists (pp. 57-76). Beverly Hills, CA: Sage.

Bruning, J. L., KINTz, B. L. (1977). Computational handbook of statistics (2nd ed.). Glenview, IL: Scott, Foresman.

BugelsKi, B. R., a Alampay, D. A. (1961). The role of frequency in developing perceptual sets. Canadian Journal of Psychology, 15. 205-211.

Carmichael, L., Hogan, H., Walter, A. (1932). An experimental study of the effect of language on the reproduction of visually perceived form. Joumal of Experimental Psychology, 15, 73-86.

CASEY, E. (1976). Imagining: A phenomenological study. Bloomington, IN: Indiana University Press.

Chambers, D., \& Reisberg, D. (1985). Can mental images be ambiguous? Joumal of Experimental Psychology, 11, 317-328.

Feldman, J., BALLARD, D. (1982). Connectionist modeis and their properties. Cognitive Science, 6, 205-254.

Finke, R. A. (1980). Levels of equivalence in imagery and perception. Psychological Review, 87, 113-132.

FiNKE, R. A. (1985). Theories relating mental imagery to perception. Psychological Bulletin, 98, 236-259.

Finke, R. A. (1989). Principles of mental imagery. Cambridge, MA: MIT Press.

Finke, R. A., Pinker, S., \& Farah, M. J. (1989). Reinterpreting visual patterns in mental imagery. Cognitive Science, 13, 51-78. 
Fisher, G. H. (1976). Measuring ambiguity. American Journal of Psychology, 80, 541-557.

FoDOR, J. (1981). Imagistic representation. In N. Block (Ed.), Imagery (pp. 63-86). Cambridge, MA: MIT Press.

FolK, M. D., \& LCE, R. D. (1987). Effects of stimulus complexity on mental rotation rate of polygons. Journal of Experimental Psychology: Human Perception \& Peformance, 13, 395-404.

Girgus, J. J., Rock, I. \& EGATz, R. (1977). The effect of knowledge of reversibility on the reversibility of ambiguous figures. Perception \& Psychophysics, 22, 550-556.

GoRDON, R. (1949). An investigation into some of the factors that favour the formation of stereotyped images. British Journal of Psychology, 39, 156-167.

Hinton, G. E. (1979a). Imagery without arrays. Behavioral \& Brain Sciences, 2, 555-556.

Hinton, G. E. (1979b). Some demonstrations of the effects of structural descriptions in mental imagery. Cognitive Science, 3, 231-250.

Hinton, G. E., Parsons, L. M. (1981). Frames of reference and mental imagery. In J. Long \& A. Baddeley (Eds.), Attention and Performance $I X$ (pp. 261-277). Hillsdale, NJ: Erlbaum.

Hochberg, J. (1968). In the mind's eye. In R. N. Haber (Ed.), Contemporary theory and research in visual perception (pp. 309-331). NY: Holt, Rinehart \& Winston.

Hofrman, D. D., \& Richards, W. A. (1985). Parts of shape recognition. In S. Pinker (Ed.), Visual cognition (pp. 65-96). Cambridge, MA: MIT Press.

Hyman, I. E., \& NeIsser, U. (1991). Reconstruing mental images: Problems of method (Emory Cognition Project Tech. Rep. No. 19). Atlanta, GA: Emory University.

JASTROW, J. (1900). Fact and fable in psychology. Boston and New York: Houghton, Mifflin.

JolICOEUR, P. (1985). The time to name disoriented natural objects. Memory \& Cognition, 13, 289-303.

Jolscoevr, P. (1988). Mental rotation and the identification of disoriented objects. Canadian Journal of Psychology, 42, 461-478.

Kinlstrom, J. F., Gusky, M. L., Peterson, M. A., Harvey, E. M., \&ose, P. M. (1991). Vividness and control of mental imagery: A psychometric analysis. Journal of Mental Imagery, 15, 133-142.

Kolers, P. (1983). Perception and representation. Annual Review of Psychology, 34, 129-166.

KossLYN, S. (1980). Image and mind. Cambridge, MA: Harvard University Press.

Kosslyn, S., Pinker, S., Smuth, G. E., \& Shwartz, S. P. (1979). On the demystification of mental imagery. Behavioral \& Brain Sciences, 2, 535-581.

Kosslyn, S., Reiser, B. J., Farah, M. J., \& Fliegel, S. L. (1983). Generating visual images: Limits and relations. Journal of Experimental Psychology: General, 112, 278-303.

МАС̆, E. (1959). The analysis of sensations and the relation of the physical to the psychical (C. M. Williams, Trans.; rev. and suppl. by S. Waterlow). New York: Dover. (Original work published 1906)

MAKI, R. H. (1986). Naming and locating the tops of rotated figures. Canadian Joumal of Psychology, 40, 368-387.

MARKS, D. F. (1973). Visual imagery in the recall of pictures. British Joumal of Psychology, 64, 17-24.

MARR, D. (1977). Analysis of occluding contour. Proceedings of the Royal Society of London: Series B, 197, 441-475.

MARR, D. (1982). Vision. New York: W. H. Freeman.

MARR, D., NishimARA, H. K. (1978). Representation and recognition of the spatial organization of three-dimensional shapes. Proceedings of the Royal Society of London: Series B, 207, 187-217.

McKeown, B., \& Thomas, D. (1988). Q methodology. Newbury Park, CA: Sage.

Nunnally, J. C. (1978). Psychometric theory (2nd ed.). New York: McGraw-Hill.

PAlmer, S. E. (1977). Hierarchical structure in perceptual representation. Cognitive Psychology, 9, 441-474.

Peterson, M. A. (in press). The ambiguity of mental images: Insights regarding the structure of shape memory and its function in creativity. In B. Roskos-Ewaldsen, M. J. Intons-Peterson, \& R. E. Anderson (Eds.), Imagery, creativity, and discovery: A cognitive perspective. Amsterdam: Elsevier.

Peterson, M. A., \& Girson, B. S. (1991). Directing spatial attention within an object: Altering the functional equivalence of shape descriptions. Journal of Experimental Psychology: Human Perception \& Performance, 17, 170-182.

Peterson, M. A., Harvey, E. R., We Wedenbacher, H. (1991). Shape recognition contributions to figure-ground organization: Which route counts? Journal of Experimental Psychology: Human Perception \& Pefformance, 17, 1075-1089.

Peterson, M. A., Weidenaacher, H. M. (1987). Recognizing objects from components. In Proceedings and abstracts of the Eastern Psychological Association Meeting (p. 43). (Abstract)

Pinker, S. (1985). Visual cognition: An introduction. In S. Pinker (Ed.), Visual cognition (pp. 1-64). Cambridge, MA: The MIT Press.

Price, J. R. (1969). Studies of reversible perspective: A methodological review. Behavior Research Methods \& Instrumentation, 1, 102-106.

REED, S. K. (1974). Structural descriptions and the limitations of visual images. Memory \& Cognition, 2, 329-336.

ReISBERG, D., CHAMBERS, D. (1991). Neither pictures nor propositions: What can we learn from a mental image? Canadian Journal of Psychology, 45, 288-302.

Rock, I. (1973). Orientation and form. New York: Academic Press.

Rock, I., \& Mrtchner, K. (in press). Further evidence of failure of reversal of ambiguous figures by uninformed subjects. Perception.

ShePARD, R. N., a CoOPER, L. A. (1982). Mental images and their transformations. Cambridge, MA: MIT Press/Bradford.

SHEPARD, S., METZLER, D. (1988). Mental rotation: Effects of dimensionality of objects and type of task. Joumal of Experimental Psychology: Human Perception \& Performance, 14, 3-11.

Simon, H. (1967). An information-processing explanation of some perceptual phenomena. British Journal of Psychology, 58, 1-12.

StePHENSON, W. (1953). The study of behavior: $Q$-sort technique and its methodology. Chicago: University of Chicago Press.

TARR, M., \& Pinker, S. (1989). Mental rotation and orientation dependence in shape recognition. Cognitive Psychology, 21, 233-282. TINBERGEN, N. (1948). The study of instinct. Oxford: Oxford University Press.

\section{NOTES}

1. We assessed the goodness of the parts of the duck/rabbit figure used in Experiments 1 and 2 at the same time as we assessed the goodness of the parts of the snail/elephant figure used in Experiment 4. Half the subjects rated the parts of the duck/rabbit figure first; the other half rated the parts of the snail/elephant figure first.

2. Fifteen subjects who reported that their images resembled both a duck and a rabbit were replaced by other subjects. Note that this is a strict criterion, because at least some of these subjects may have reversed the image rather than the picture.

3. Most of the additional reversals in the lower half of the table were reconstruals rather than reference-frame realignments. Only one of the additional reversals tabled under All Reversals in Experiment 1 (good parts condition) and three in Experiment 2 (one in the full-version condition and two in the poor parts condition) may have been referenceframe realignments. We did not group these reversals with the duck/rabbit reversals, because in Experiments 1 and 2 we had not asked subjects to verify the reference frames for their interpretations.

4. The tests of significance for these proportions were found in Bruning and Kintz (1977). When comparing our proportions against expected values, we could not use an expected value of 0 , which is the correct expected value based on Chambers and Reisberg's (1985) experiments. Accordingly, we calculated an expected value of .02 , using the following reasoning. Chambers and Reisberg tested a total of 55 subjects, not one of whom reported a reversal in imagery. If we suppose that the next subject might have reported a reversal, we arrive at .02 as a conserva- 
tive theoretical estimate of the predicted probability of reversal. Because our predictions regarding both the presence of reversals in imagery and the differences between the good and poor parts conditions were clearly unidirectional, we employed one-tailed tests for those comparisons. All other tests were two-tailed.

5. Two subjects who reported seeing both alternatives in the pictures were excused from the experiment and replaced by other subjects.

6. The judges who evaluated the drawings were each paid $\$ 5.00$ for their services.

7. We had to replace 39 subjects who were able to reverse between the duck and rabbit interpretations while viewing the picture; hence, $25 \%$ of the subjects had to be dismissed. This proportion is extremely large, and might have decreased had we shortened the duration of exposure of the Jastrow duck/rabbit figure. Note, however, that the exposure duration was the same as that used by Chambers and Reisberg (1985).

8. We found only one other item in the set of classic ambiguous figures whose reversal involves reconstrual only without a concomitant reference-frame reversal-the rat/man figure (Bugelski \& Alampay, 1961). We selected the snail/elephant figure for these experiments because it is simpler and thus probably easier to construct and maintain in imagery.

(Manuscript received March 7, 1991; revision accepted for publication August 14, 1991.) 